\title{
Polyphenolic extracts from the olive mill wastewater as a source of biopesticides and their effects on the life cycle of the Mediterranean fruit fly Ceratitis capitata (Diptera, Tephriditae)
}

\author{
Vincenzo Di llio $^{1,2} \cdot$ Massimo Cristofaro ${ }^{1}$ \\ Received: 27 February 2020 / Accepted: 9 July 2020 / Published online: 12 August 2020 \\ (C) The Author(s) 2020
}

\begin{abstract}
The Mediterranean Fruit Fly Ceratitis capitata (Wiedemann) (Diptera, Tephriditae) is an important pest in the Mediterranean region causing severe economic losses. Currently, pyrethroids are the most common insecticides used in the control of the Medfly. However, the demand for biopesticides is growing due to the necessity to limit the use of hazardous chemical pesticides in the context of the integrated pest management. In this context, a valid alternative is the use of plant derived pesticides with a selective action against target pests and a shorter persistence in ecosystems.

Among plant products, olive tree phenolic and polyphenolic compounds show potent bioactive properties as insecticides and growth regulators. The olive mill wastewater is an important source of these compounds.

We are reporting here that the polyphenolic fractions of the olive mill wastewater, show ovicidal effects in terms of reduction of the hatching rate, whereas the larval development is not affected by the treatments.

On the adults, we show that selected fractions induce a complete block of the fecundity of the females probably due to an induced disruption of the oogenesis.

These results suggest that the polyphenolic fractions derived from the olive mill wastewater can be used as a strong natural chemosterilant against the Mediterranean Fruit fly and can be considered as a putative ovicidal agent.
\end{abstract}

Keywords Mediterranean fruit Fly $\cdot$ Ceratitis capitata $\cdot$ Biopesticices $\cdot$ Olive mill wastewater $\cdot$ Polyphenols

\section{Introduction}

Human population demand for food is an increasing global concern. Crop losses by pests contribute to this critical situation not only by the implicit loss of crops and foodstuff but by the necessity to limit the use of hazardous chemical pesticides due to the fast-growing pest-resistance. In this context, demand for biopesticides is growing due to the increase of areas under integrated pest management worldwide.

Massimo Cristofaro

massimo.cristofaro.cas@enea.it

ENEA C.R. Casaccia, Via Anguillarese, 30, 00123 Rome, Italy

2 BBCA Onlus, (Biotechnological and Biological Control Agency), Via Angelo Signorelli, 105, 00123 Rome, Italy
The Mediterranean Fruit Fly Ceratitis capitata (Wiedemann) is one of the most important pests in the Mediterranean region. It causes severe economic losses having the possibility to infest over 250 types of fruits (Fimiani 1989). The Medfly originated in the Afrotropical Region and have spread worldwide, mainly through human activities (Maddison and Bartlett 1989; De Meyer et al. 2002). The life cycle requires 20-90 days, depending on the climatic conditions (Metcalf and Flint 1962). After mating, females search for a suitable host were lays 2-20 eggs under the skin of the fruit (Jang 1995). Larvae feed in the pulp, where they cause the most important economic damage, then exit from the fruit and pupate in the soil.

Currently, pyrethroids are the most common insecticides used in the control of the Medfly. A variety of synthetic pesticides have been used during the last 40 years to control the infestations instigating by different pests, often giving economical and effective results and enhancing the production 
of agricultural commodities but causing adverse effects not only to environment but also to non targeted insects (including beneficial insects), vertebrate animals and also causing toxicity to human. (Bughio and Wilkins 2004; Magana et al. 2008; Vontas et al. 2011; Abdelatti and Hartbauer 2020).

Indeed, most conventional insecticides used to control fruit flies have been banned, so bait stations can be a suitable alternative. Semiochemicals are important for fruit flies to locate their host fruit and to reproduce, however analytical work has still to be conducted, as many semiochemicals associated with fruit flies' life strategies have yet to be identified (Sarles et al. 2015).

A valid alternative to chemical insecticides is the use of plant derived pesticides that assure a selective action against target pests and a shorter persistence in ecosystems (Mishra et al. 1990; Stark and Walter 1995; Di Ilio et al. 1999; Enyiukwu et al. 2014; Shivanandappa and Rajashekar 2014).

Among natural products, it has been reported that olive tree (Olea europaea L.) derivatives show potent biological activities for the control of several insect pests. The olive fly Bactrocera oleae is actively repelled by olive leaf extract (Lo Scalzo et al. 1994), while Barbouche et al. (1996) have reported anti-feeding effect on Schistocerca gregaria. The insecticidal properties of leaf extracts were assessed in laboratory against the olive psyllid, Euphyllura olivina (Ouguas et al. 2010), the gypsy moth Lymantria dispar (Hemmingi et al. 2000) and the pea aphid Acyrthosiphon pisum (Golawska et al. 2008). Many authors agree that the insecticidal and growth regulation effects are due to phenolic and polyphenolic compounds contained in the olive tree leaves (Capasso et al. 1992; Lo Scalzo et al. 1994).

The most known compound present in the leaves and drupes is the Oleuropein, a polyphenol responsible for the bitterness of ripe olives. Oleuropein is also considered an anti-neurodegenerative compound as well as an enhancer of the immune system (Pantano et al. 2016; Jemai et al. 2009; Zari and Al-Attar 2011).

An important source of olive polyphenols is the olive mill wastewater (OMWW) that contains many interesting compounds for the control of pests in agriculture (Capasso et al. 1992). OMWW is the major by-product of the olive oil production, it has a high acidity ( $\mathrm{pH} \sim 4.5$ ), high salt content, high concentrations of organic compounds such as phenols, polyphenols and carbohydrates (Chowdhury et al. 2013).

The present study was conducted to determine the effects of three polyphenolic fractions of the OMWW as a source of new natural biopesticides using the Medfly as a model insect. The effects of the polyphenolic solutions were studied in all stages of the life cycle in laboratory conditions. In particular, the ovicidal properties of the fractions, the effects on larval development and the alterations of the longevity, the fertility and the fecundity of the adults induced by the polyphenolic extracts were evaluated.

\section{Materials and methods}

\section{Insects}

The laboratory population of $C$. capitata was reared at constant conditions of temperature $\left(27 \pm 2{ }^{\circ} \mathrm{C}\right), 60 \pm 10 \% \mathrm{RH}$, and a photoperiod 16:8 (L:D) h (Vargas 1989) in climatic chambers at ENEA Casaccia Research Centre, Rome, Italy.

Adults were reared in a sleeve cage $(30 \times 30 \times 30 \mathrm{~cm})$, with a dispenser for water and a source of artificial diet consisting of a 3:1 volumetric mixture of sucrose and yeast hydrolysate (Vargas 1989). Adult females lay eggs perforating the cage nets with the ovipositor (Economopoulos and Judt 1989; Di Ilio et al. 1999). The eggs were collected in a container with tap water placed under the cage. About 200 eggs were seeded in a $10 \mathrm{~cm}$ diameter Petri dish on the surface of a solid larval medium prepared according to the recipe by Economopoulos (1992). Larvae fed inside the larval medium until ready for popping out of the petri dish. The petri dish was then placed into a container over a layer of clean sand to allow pupation. Pupae were collected daily sieving the sand and placed in a $10 \mathrm{~cm}$ petri dishes for adult emergence. Randomly selected males and females emerging from pupae were used for the experiments of adult toxicity while the surplus was transferred into the rearing cage.

\section{OMWW fractions}

Polyphenolic fractions from the OMWW were supplied by the group of Biotechnology and Agroindustry of the ENEA Casaccia Research Centre (Rome, Italy). Briefly, the OMWW was centrifuged and micro-filtered to remove residues of suspended compounds and residues of oil.

The obtained solution was then ultra-filtered to remove proteins and other macro molecules from the solution. This ultra-filtrate solution was used in the bioassays labelled as UF and contain polyphenols of molecular weight greater that $1000 \mathrm{Da}$. The permeate was subsequently nano-filtered. The nano-filtered solution contains polyphenols with a molecular weight between 1000 and $300 \mathrm{Da}$ and was indicated in the bioassays as NF. The nano-filtered solution was then subjected to reverse osmosis to separate polyphenols with a molecular weight smaller than $300 \mathrm{Da}$. The reverse osmosis gave ultrapure water fraction rich in low molecular weight polyphenols and was used in the bioassays with the label of OI. The described filtration process has been patented (Patent $\mathrm{n}$. WO2005/123603A1, 2005). Identification and relative abundance of polyphenols in the solutions was not evaluated.

Each one of the three polyphenolic fractions (UF, NF and OI) was serially diluted with distilled water to obtain eventually 3 solutions at decreasing concentration numbered from 1 to 3 to be used in the biotests. The solutions 1 is the most concentrated and correspond to the undiluted fraction. This mixture was 
diluted with distilled water $1: 1(\mathrm{v}: \mathrm{v})$ to obtain the solutions 2 . In turn, the solutions 2 was diluted again with distilled water 1:1 (v:v) to obtain the solutions 3 that was therefore the less concentrated. In total, 9 solutions were prepared and the corresponding treatment groups were labelled as follows: UF1, UF2, UF3 for the ultra-filtered fraction; NF1, NF2, NF3 for the nano-filtered fraction and OI1, OI2 and OI3 that correspond to the dilutions of the reverse osmosis fraction.

\section{Egg toxicity}

Randomly selected eggs collected from the water under the rearing cage were allowed to hatch individually in the pits of a 24 well plate. 10 eggs were used for each replication distributed separately in the wells. Each well was filled with $500 \mu \mathrm{l}$ of the assigned test solution obtained from each polyphenolic fraction. Distilled water was used for the control group. After $72 \mathrm{~h}$ the number of first instar larvae was recorded and the hatching rate was calculated for each treatment group as the ratio between the number of first instar larvae obtained and the number of eggs seeded. Twelve replications were carried out.

\section{Larval toxicity}

The larval medium for larval toxicity trials was prepared according to the recipe by Economopoulos (1992). The three solutions of each polyphenolic fraction were integrated in the larval medium in a 4:1 weight proportion (larval medium: OMWW solution). Control medium was prepared in the same way incorporating distilled water in the larval food. 30 eggs were seeded in a $5 \mathrm{~cm}$ diameter Petri dish on the surface of the larval medium and maintained according to the method described above for the rearing. The number of pupae obtained was recorded. Pupae obtained from each treatment group were kept separated and the adult emergence was recorded. Four replications were carried out.

\section{Adults toxicity}

Newly emerged couples of $C$. capitata adults, randomly selected from a homogenous laboratory population, were placed in small Plexiglas cages $(4 \times 8 \times 17 \mathrm{~cm})$ containing a water dispenser. Each cage had a $2.5 \mathrm{~cm}$ round opening covered with a light net for oviposition (Economopoulos and Judt, 1989). Each cage was placed over a small container with water for the collection of eggs. Experimental food was prepared mixing yeast hydrolysate and sucrose as described above. The three solutions obtained from each polyphenolic fraction were used to dilute the solid diet for the adults in a $1: 1$ rate (w:w). Control food was prepared using distilled water only. The liquid food obtained was administered to each couple by means of $20 \mu \mathrm{l}$ glass capillaries inserted through a $2 \mathrm{~mm}$ hole drilled on the wall of the cage according to the method described by Ja et al. (2007) conveniently adapted for the medfly. Flies were kept in this condition for 16 days during which the mortality was recorded every other day. The glass capillaries were controlled and replaced every other day and the amount of consumed food was recorded. The fecundity of each couple was evaluated by collecting and counting the eggs produced daily. The eggs collected from the couples in each treatment group were allowed to hatch in a damp environment to obtain data on the fertility of the couples. The fertility was evaluated as eclosion rate, intended as number of larvae by the total number of eggs. Four replications were carried out.

\section{Statistical analysis}

The data of the bioassays of all experiments were analysed by ONE-WAY-ANOVA with a post-hoc LSD tests using GenStat 64-bit Release 17.1 for Windows.

\section{Results and discussion}

The objective of this work was to determine, in laboratory conditions, the effects of polyphenolic fractions derived from the OMWW on the life cycle of the Mediterranean Fruit Fly, C. capitata, chosen as a model insect.

The medfly larvae were reared on artificial medium and oviposition was artificially controlled (Economopoulos and Judt 1989; Di Ilio et al. 1999). The artificial medium (Economopoulos 1992 and b) was preferred to semi natural conditions were oviposition occurs on fruits because it is possible to control the fecundity of the females, the fertility of the eggs and the larval development. The artificial rearing of the medfly is well established, various mediums have been proposed without affecting eggs hatching and growth of the larvae (Vargas 1989; Economopoulos et al. 1990; Economopoulos 1992 and b; Bravo and Zucoloto 1998).

\section{Egg toxicity}

Figure 1 shows the hatching rate of the eggs treated with UF, $\mathrm{NF}$ and $\mathrm{OI}$ at three different concentrations. It can be observed that the NF fraction elicited the greater toxicity on the eggs of the medfly.

The fertility of the eggs in the control group is not different from the wild $C$. capitata populations. In fact, the hatching rate (number of 1st instar larvae by number of eggs) observed in the control group was $0.91 \pm 0.09$ in line to what reported by Rössler (1975) for the fertility of wild medfly populations. The ONE-WAY-ANOVA test showed that there is a highly significant difference among the treatment groups $(F=20.02$; $p<.001$; d.f. $=119)$. In particular, the LSD test showed that the NF treatments were significantly different from all other treatment groups $(\alpha=0.05)$, while no significant difference was 
Fig. 1 Hatching rate in the different treatment groups obtained by the ratio between the number of first instar larvae and the total number of eggs treated per group of treatment. Standard Deviation is indicated as error bars

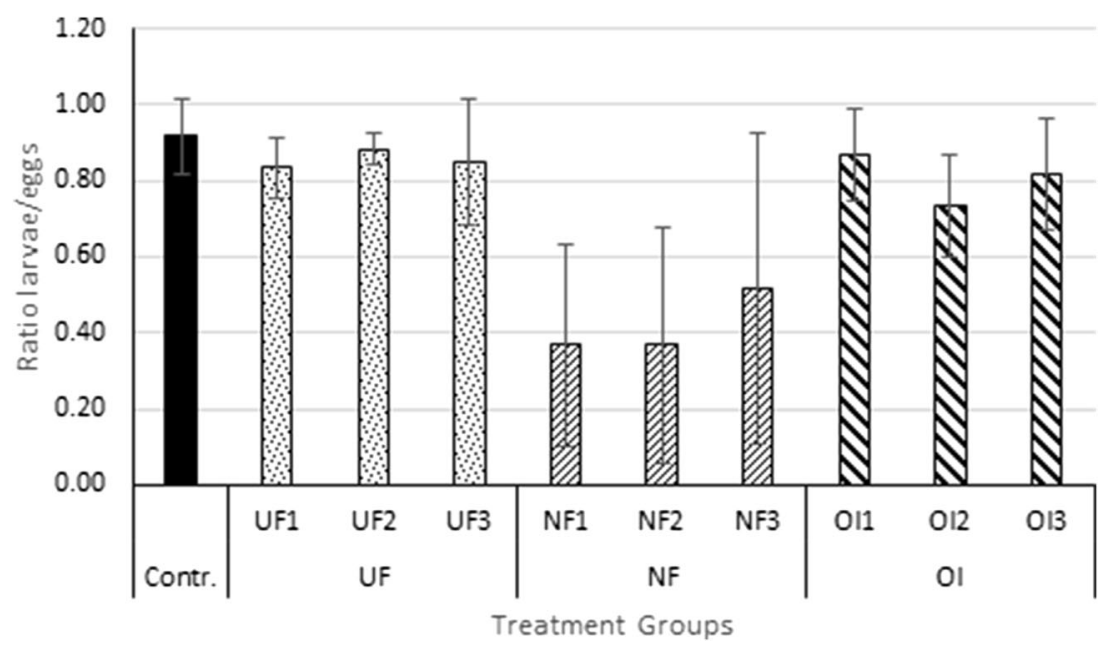

detected among OI, UF and control treatment groups. These data demonstrate that the nanofiltered fraction of the OMWW has the most interesting ovicidal properties. The ONE-WAYANOVA test showed also that there is not a significant difference among the three different concentrations of each fraction allowing to conclude that none of the fraction acts on a dose dependent basis. The observed ovicidal effects can be exploited to control insects that show insecticide resistance, alone or in association with other insecticides and insect growth regulators as reported for example by El-Guindy et al. (1983). OMWW polyphenolic based ovicides can also be used to control the hatching rate of mosquito eggs as reported for other botanical extracts (Ervatamia coronaria and Caesalpinia pulcherrima) against Anopheles stephensi, Aedes aegypti, and Culex quinquefasciatus (Govindarajan et al. 2011).

\section{Larval toxicity}

Unlike to what was exposed for the eggs, the treatment of the larval medium did not give appreciable results in terms of mortality and in terms of regulation of the growth of the larvae. Our data on the larval survival of the control group were not different from what has been reported by other authors (Vargas 1989; Economopoulos et al. 1990; Economopoulos 1992 and b; Bravo and Zucoloto 1998). In fig. 2 it can be observed that none of the treatments of the larval medium with the three OMWW fractions gave an appreciable mortality on all larval instars. Larvae reached the pupal stage without any significative difference from the control $(\mathrm{F}=1.62 ; p=0.223$; d.f. $=39)$. Furthermore, no latent toxicity was observed as the emergence rate (adults/ pupae) for all treatment groups did not differ significantly from the control $(\mathrm{F}=1.71 ; p=0.205$; d.f. $=39)$ (Fig. 3$)$. No fagodeterrence was observed in any treatment group. Our results demonstrate that the OMWW fractions do not show larvicidal effect on C. capitata in contrast with the results of Hemming and Lindroth (2000) who observed reduced performance, increased developmental time and decreased growth rates of the gipsy moth and the forest tent caterpillar after treatment with phenolic glycosides.
Fig. 2 Pupation rate in the different treatment groups obtained by the ratio between the number of pupae obtained and the total number of eggs seeded on the larval medium per group of treatment. Standard Deviation is indicated as error bars

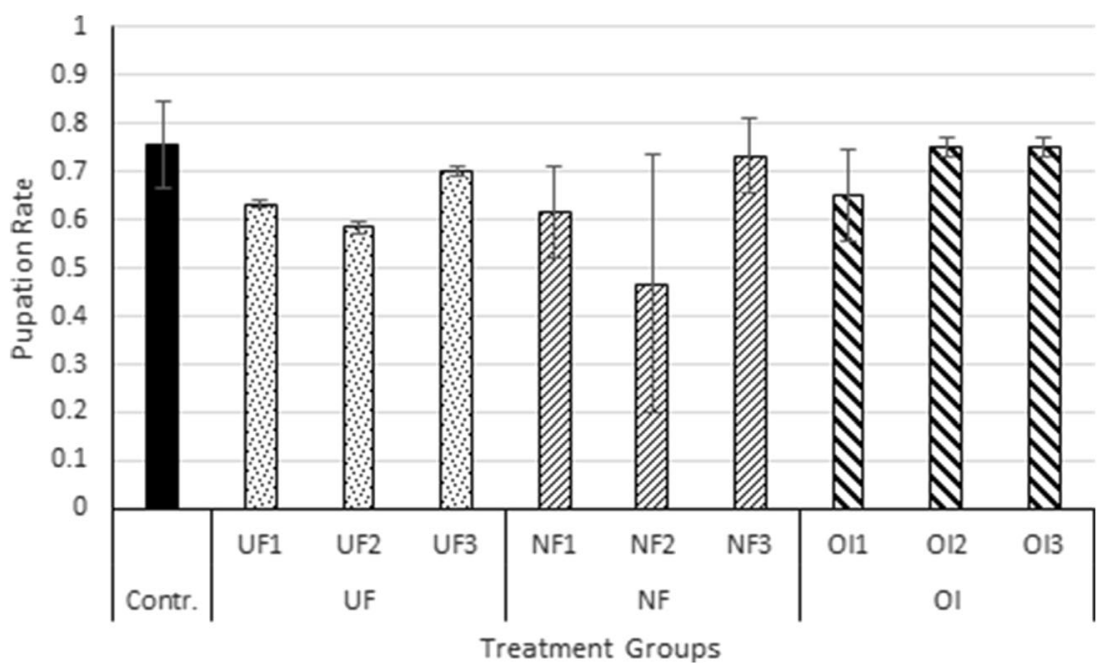


Fig. 3 Emergence rate in the different treatment groups obtained by the ratio between the number of adults emerged from pupae obtained after treatment of the larval medium and the total number of pupae collected per group of treatment. Standard Deviation is indicated as error bars

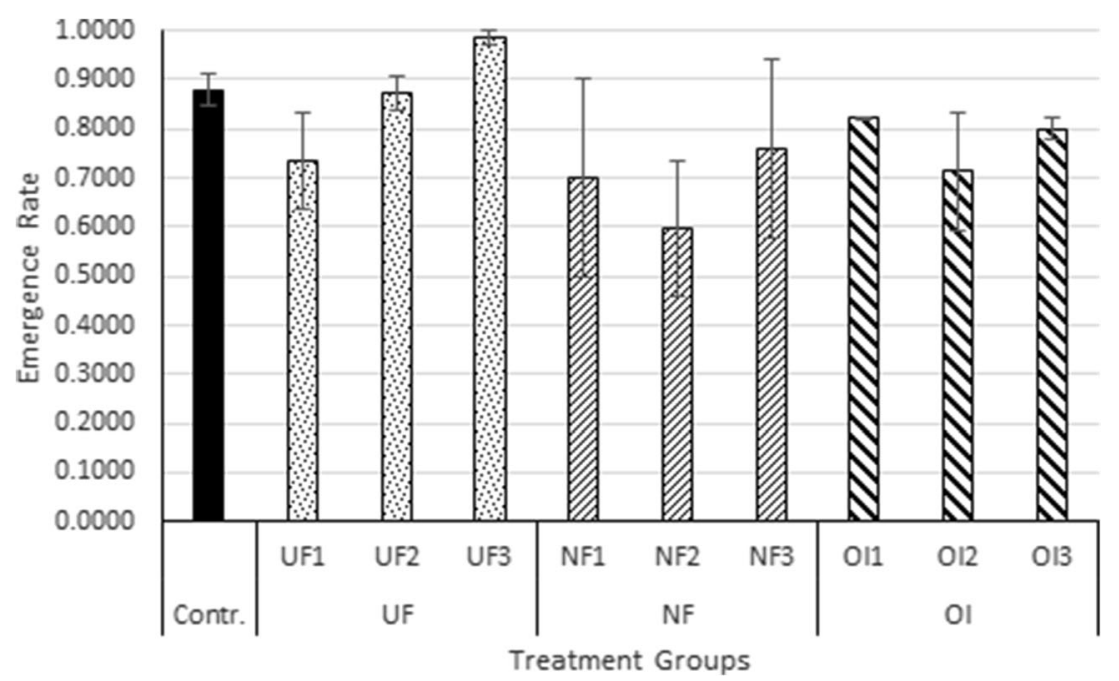

\section{Adults toxicity}

The mortality of $C$. capitata adults treated with the three OMWW polyphenolic fractions was not appreciable during the 16 days of the experiment in any of the treatment groups confirming that none of the OMWW fractions tested possess adulticidal proprieties.

As regards the consumption of food, data showed that there is a significant difference among the groups $(\mathrm{F}=$ $5.25 ; p=0.002$; d.f. $=335)$, but it should be remarked that the LSD test $(\alpha=0.05)$ show that only the NF is significantly different from the control while no significant difference can be admitted for both the UF and the OI fractions. This is visible in Fig. 4 where it can be observed that a limited fagodeterrence is admissible only for NF. The observation of the trend of the consumption of food, displayed in Fig. 5, confirms that only the fraction NF owns fagodeterrent properties since the control line is constantly above the lines of the different concentrations of this fraction (Fig. 5B). On the contrary, fig. 5A and $\mathrm{C}$, regarding respectively the UF and the OI fractions show that trends are not significantly different respect to the control.

Adults fed with OMWW fractions laced food gave however interesting results in terms of reduction of the fecundity. Figure 6 clearly shows how the production of eggs is completely blocked in the NF treatment group at every dilution. The ONE-WAY-ANOVA analysis confirms the high significant difference among groups $(\mathrm{F}=6.40 ; p=0.005$; d.f. $=39)$. The LSD test $(\alpha=0.05)$ further proves that the fecundity of the UF and OI treatment groups are not significantly different from the control. Given the complete abolition of the fecundity in the NF treatment group at all dilutions, further experiments are envisaged to identify the compound or the pool of compounds that block the fecundity.

An important issue is represented by the fact that, since the NF is derived directly from UF by nanofiltration, the unidentified compounds that blocks the oogenesis in the NF treated group should be presented in the UF too. For this reason, it should be expected that the treatment with the UF should give the same results than NF in terms of reduction of fecundity in
Fig. 4 Average food consumption in microliters in the different treatment groups at different concentrations. Data are obtained measuring the amount of food consumed every other day for 16 days. Standard Deviation is indicated as error bars

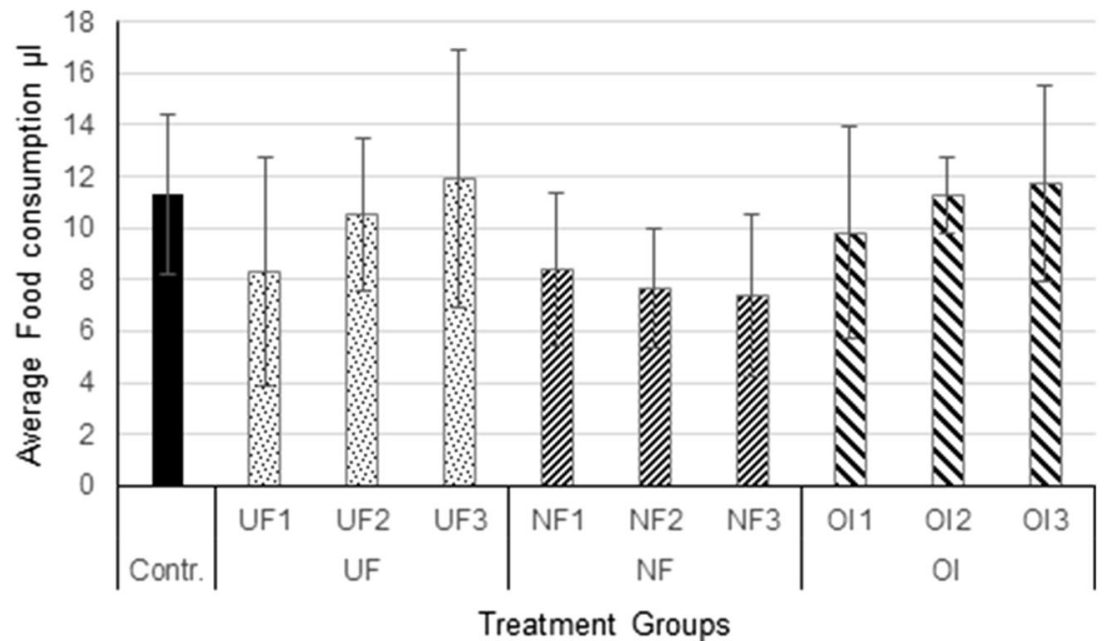



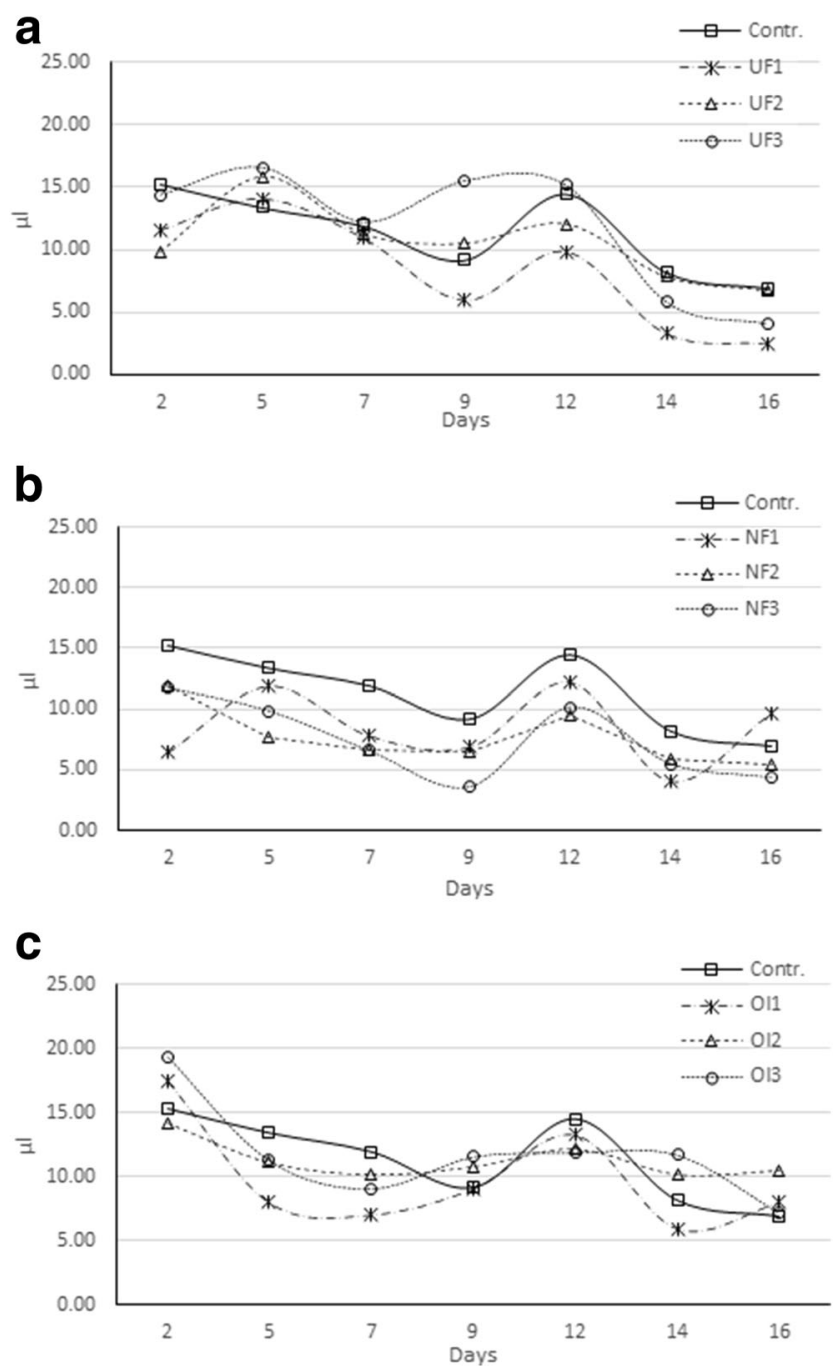

Fig. 5 Daily trends of food consumption in microliters in the different treatment groups at different concentrations. A: trends of food consumption of the different concentrations of UF; B: trends of food consumption of the different concentrations of NF; C: trends of food consumption of the different concentrations of OI. Data are obtained measuring the amount of food consumed every other day for 16 days the medflies. Surprisingly, the LSD test $(\alpha=0.05)$ shows that the UF treatment groups are not significantly different from the control, although, looking at Fig. 6, a dose dependent effect can be admitted, but further experimental details are needed to corroborate this hypothesis. However, data allows to hypothesize the existence of inhibiting factors that are removed from the UF by nanofiltration so that they are present into the UF fraction but not anymore in the NF fraction. On the contrary, the putative sterilizing compound in the NF fraction is separated during the reverse osmosis process so that it is not present anymore in the OI ultrapure water. Following this, we can admit that one or more chemosterilization factors are probably polyphenolic compounds with a molecular weight between 0.3 and 1 KDalton. Further chemical analyses are indeed envisaged to identify the putative blocking factor and the polyphenolic composition of the different fractions.

The abolition of the fecundity induced by NF is more likely attributable to a disruption of the oogenesis of the female rather than a block in the spermatogenesis in the males since unmated females that usually produce a limited number of sterile eggs in laboratory conditions (personal observation).

Finally (Fig. 7), we observed that the hatching rate of the eggs produced by treated couples of the UF and OI treatment groups is not significantly different from the control. The consequent conclusion is that there is not an appreciable reduction of the fertility of the eggs following the treatment of the adults.

Taken together these data confirm that the use of plant derived pesticides should assure an effective pest control, a selective activity against target pests and a shorter persistence in ecosystems as reported by several authors (Mishra 1990; Stark and Walter 1995; Di Ilio et al. 1999; Enyiukwu et al. 2014; Shivanandappa and Rajashekar 2014). In this scenario, we confirm what reported by other authors that Olea europaea contains several interesting compounds (Capasso et al. 1992) with repellent and anti-feeding proprieties against many insect pests (Lo Scalzo et al. 1994; Barbouche et al. 1996;
Fig. 6 Average fecundity of flies in the different treatment groups at different concentrations expressed as total number of eggs produced during the 16 days of treatment. Standard Deviation is indicated as error bar

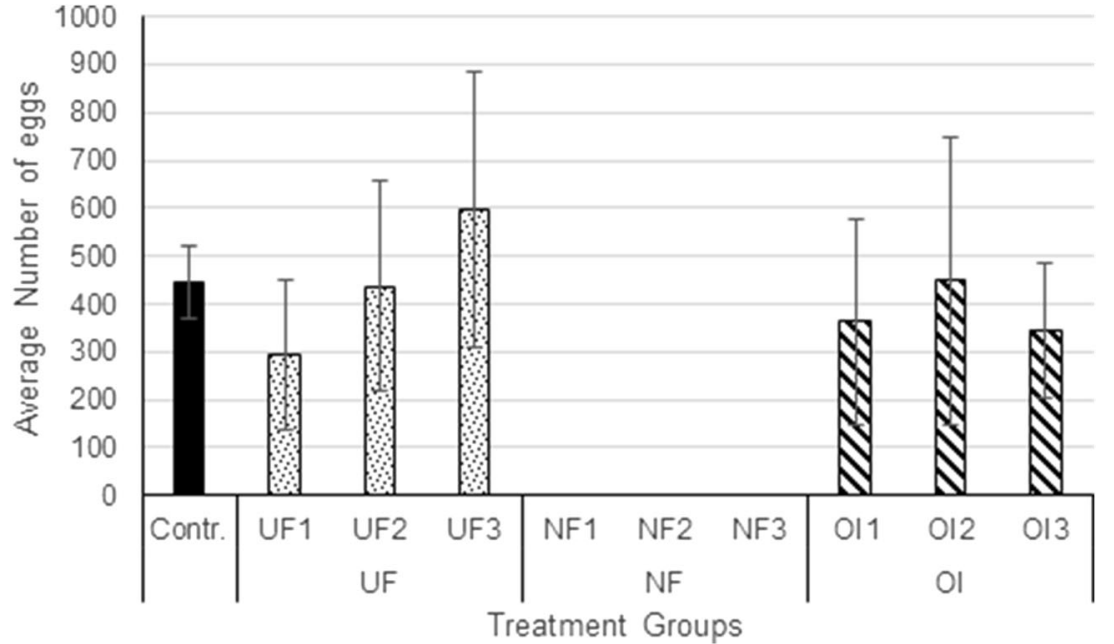


Fig. 7 Fertility of the eggs laid by females in treated with the different OMWW fractions. The hatching rate was obtained by the ratio between the number of first instar larvae and the total number of eggs randomly selected among those laid by females in the treatment groups. The number of 1st instar larvae in the NF treatment group is not represented because the NF treated females did not lay any egg as shown in Fig. 6. Standard Deviation is indicated as error bars

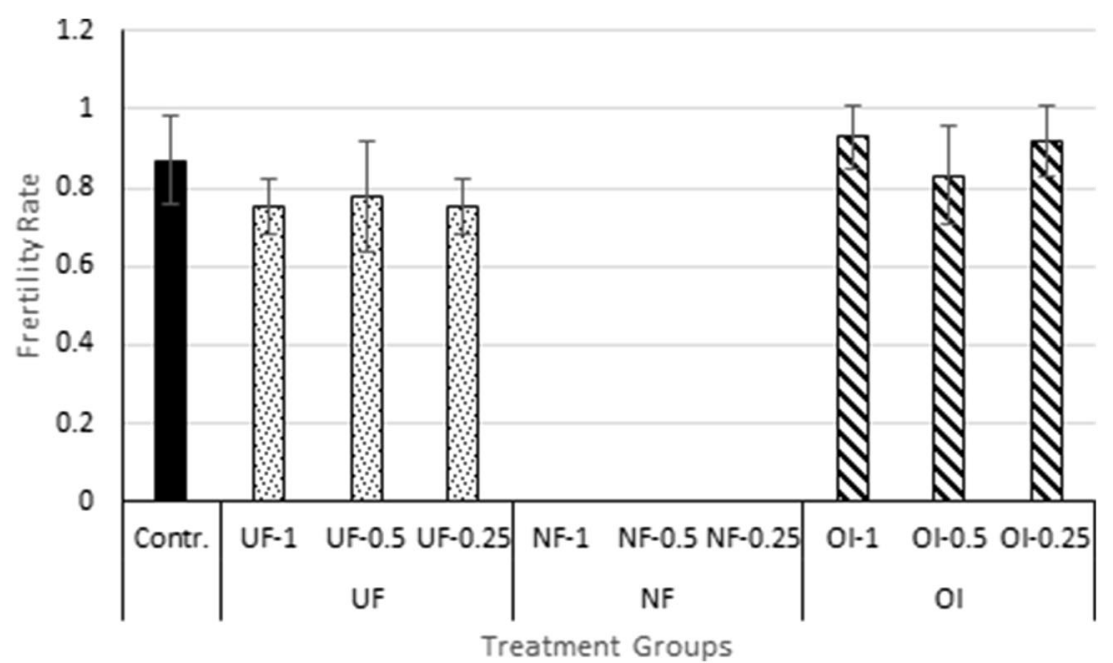

Hemmingi et al. 2000; Golawska et al. 2008; Ouguas et al. 2010). In addition to these findings, we demonstrated that some olive mill wastewater compounds own also growth regulation properties, interfering with the oogenesis of the Medfly at sublethal doses.

\section{Conclusions}

This work shows the effect of polyphenolic extracts from OMWW as biopesticides against Mediterranean fruit fly Ceratitis capitata and also their role in its life phases. This type of work meets current need in pest management and crop protection and should be considered as an initial approach to the use of OMWW as novel source of biopesticides. We are reporting here the effects of three polyphenolic fractions of the OMWW, obtained by a series of microfiltrations, on the entire life cycle of the Mediterranean Fruit Fly C. capitata.

In the experimental conditions set, only the nanofiltered fraction have interesting effects on the eggs of the Medfly in terms of reduction of the hatching rate, while the larval development is not affected by the treatments with any of the three fractions.

As regards the adults, none of the three fractions affects the survival of the flies and only a limited fagodeterrence was elicited by the nanofiltrated solution. The most interesting effect observed regards the fecundity of the flies. In fact, the nanofiltered solution induces a complete block of the production of eggs in the medfly couples. Further experimentation is necessary to identify the nature and the relative abundancy of the compound, or the pool of compounds of interest, along with the identification of possible inhibiting factors in the OMWW solutions.

The extracts from the olive tree can comprise a significant resource in pest control and, to this extent, assays on the effects of these mixtures on beneficial species are also envisaged. However, their importance for integrated pest management program could be quite significant and well worth further studies.

Acknowledgements Open access funding provided by Ente per le Nuove Tecnologie, l'Energia e l'Ambiente within the CRUI-CARE Agreement. The authors thanks Dr. Massimo Pizzichini for the supply of the three polyphenolic fractions. We also thank workers at the ENEA C.R.Casaccia for the technical support in the Medfly rearing. This work was supported by internal funds of the ENEA C.R. Casaccia, Department UTAGRI-ECO and by funds from the Foundation BBCA Onlus.

Availability of data and material Not applicable.

Code availability Not applicable.

Author contribution statement VDI and MC conceived and designed research. VDI conducted experiments. VDI and MC analyzed data. VDI wrote the manuscript. All authors read and approved the manuscript.

Funding The research was entirely supported by ENEA (Italy).

\section{Compliance with ethical standards}

Conflict of interest Not applicable.

Open Access This article is licensed under a Creative Commons Attribution 4.0 International License, which permits use, sharing, adaptation, distribution and reproduction in any medium or format, as long as you give appropriate credit to the original author(s) and the source, provide a link to the Creative Commons licence, and indicate if changes were made. The images or other third party material in this article are included in the article's Creative Commons licence, unless indicated otherwise in a credit line to the material. If material is not included in the article's Creative Commons licence and your intended use is not permitted by statutory regulation or exceeds the permitted use, you will need to obtain permission directly from the copyright holder. To view a copy of this licence, visit http://creativecommons.org/licenses/by/4.0/. 


\section{References}

Abdelatti ZAS, Hartbauer M (2020) Plant oil mixtures as a novel botanical pesticide to control gregarious locusts. J Pest Sci 93:341-353

Barbouche N, Dhouib S, Ammar M, Ben Hamouda MH (1996) Action de trois substrats alimentaires: Bersim, faux poivrier et olivier Sur le développement de la cuticule chez le criquet pèlerin Schistocerca gregaria. Annales de l'Institut National de Recherches Agronomiques de Tunis 69:131-146

Bravo ISJ, Zucoloto FS (1998) Performance and feeding behavior of Ceratitis capitata: comparison of a wild population and a laboratory population. Entomologia Experimentalis et Applicata 87: $67-72$

Bughio FM, Wilkins RM (2004) Influence of malathion resistance status on survival and growth of Tribolium castaneum (Coleoptera: Tenebrionidae), when fed on flour from insect resistant and susceptible grain rice cultivars. J Stored Prod Res 40:65-75

Capasso R, Cristinzio G, Evidente A, Scognamiglio F (1992) Isolation, spectroscopy and selective phytotoxic effects of polyphenols from vegetable waste waters. Phytochemistry 31:4125-4128

Chowdhury SKMMB, Akratos CS, Vayenas DV, Pavlou S (2013) Olive mill waste composting: a review. Int Biodeterior Biodegrad 85:108 119

De Meyer M, Copeland RS, Wharton RA, McPheron BA (2002) On the geographic origin of the Medfly Ceratitis capitata (Wiedemann) In Barnes BN (ed) Proceedings of 6th International Fruit Fly Symposium 6-10 May, Stellenbosch, South Africa pp 45-53

Di Ilio V, Cristofaro M, Marchini D, Nobili P, Dallai R (1999) Effects of a Neem compound on the fecundity and longevity of Ceratitis capitata (Diptera: Tephritidae). J Econ Entomol 92:76-82

Economopoulos A (1992) Adaptation of the Mediterranean fruit Fly (Diptera: Tephritidae) to artificial rearing. J Econ Entomol 85: 753-758

Economopoulos A, Al-Taweel A, Bruzzone N (1990) Larval diet with a starter phase for mass-rearing Ceratitis capitata: substitution and refinement in the use of yeasts and sugars. Entomologia Experimentalis et Applicata 55:239-246

Economopoulos A, Judt S (1989) Artificial rearing of the Mediterranean fruit Fly (Diptera: Tephritidae): size of oviposition holes. J Econ Entomol 82:668-674

El-Guindy MA, Abdel-Sattar MM, El-Refai ARM (1983) The ovicidal action of insecticides and insect growth regulator/insecticide mixtures on the eggs of various ages of susceptible and diflubenzuronresistant strains of Spodoptera littoralis boisd. Pestic Sci 14:253-260

Enyiukwu DN, Awurum AN, Nwaneri JA (2014) Efficacy of plantderived pesticides in the control of myco-induced postharvest rots of tubers and agricultural products: a review. Net Journal of Agricultural Science 2:30-46

Fimiani P (1989) Mediterranean region. In Robinson AS, Hooper G (eds): world crop pests vol 3B, fruit flies Elsevier science publishers BV Amsterdam (Nederlands) pp 141-151

Golawska S, Kapusta I, Lukasik I, Wojcicka A (2008) Effect of phenolics on the pea aphid, Acyrthosiphon pisum (Harris) population on Pisum sativum L (Fabaceae). Pestycydy/Pesticides 3-4:71-77

Govindarajan M, Mathivanan T, Elumalai K, Krishnappa K, Anandan A (2011) Mosquito larvicidal, ovicidal, and repellent properties of botanical extracts against Anopheles stephensi, Aedes aegypti, and Culex quinquefasciatus (Diptera: Culicidae). Parasitol Res 109: 353-367

Hemming JDC, Lindroth RL (2000) Effects of phenolic glycosides and protein on gypsy moth (Lepidoptera: Lymantriidae) and Forest tent caterpillar (Lepidoptera: Lasiocampidae) performance and detoxication activities. Environ Entomol 29:1108-1115

Ja WW, Carvalho GB, Mak EM, de la Rosa NN, Fang AY, Liong JC, Brummel T, Benzer S (2007) Prandiology of Drosophila and the CAFE assay. PNAS 104:8253-8256

Jang EB (1995) Effects of mating and accessory gland injections on olfactory-mediated behavior in the female Mediterranean fruit fly, Ceratitis capitata. J Insect Physiol 41:705-710

Jemai H, Feki AEL, Sayadi S (2009) Antidiabetic and antioxidant effects of hydroxytyrosol and oleuropein from olive leaves in alloxandiabetic rats. J Agric Food Chem 57:8798-8804

Lo Scalzo R, Scarpati ML, Verzegnassi B, Vita G (1994) Olea europaea chemical repellent to Dacus oleae females. J Chem Ecol 20:18131923

Maddison PA, Bartlett BJ (1989) A contribution towards the zoogeography of the Tephritidae world crop pests vol 3A, fruit flies Elsevier science publishers BV Amsterdam (Nederlands) pp 372-381

Magana C, Hernandez-Crespo P, Brun-Barale A, Couso-Ferrer F, Bride J, Castanera P, Feyereisen R, Ortego F (2008) Mechanisms of resistance to malathion in the medfly Ceratitis capitata. Insect Biochem Mol Biol 38:756-762

Metcalf CL, Flint WP (1962) Destructive and useful insects mc GrawHill book company inc 1962: pp 1087

Mishra AK, Dubey NK (1990) Fungitoxicity of essential oil of Amomum sublatu against Aspergillus flavus. Econ Bot 44:530-533

Ouguas Y, Hilal A, Elhadram I (2010) Effet biocide des extraits phénoliques oléicoles Sur les adultes du psylle de l'olivier Euphyllura olivina costa (Homoptera : Psyllidae) Sur deux variétés d'oliviers. Menara et Arbequine au Maroc Revue Ezzaitouna 11:1-15

Pantano D, Luccarini I, Nardiello P, Servili M, Stefani M, Casamenti F (2016) Oleuropein aglycone and polyphenols from olive mill wastewater ameliorate cognitive deficits and neuropathology. Br J Clin Pharmacol 83:54-62

Rössler Y (1975) Reproductive differences between laboratory-reared and field-collected populations of the Mediterranean Fruitfly, Ceratitis capitata. Ann Entomol Soc Am 68(6):987-991

Sarles L, Verhaeghe A, Francis F, Verheggen FJ (2015) Semiochemicals of Rhagoletis fruit flies: potential for integrated pest management. Crop Prot 78:114-118

Shivanandappa T, Rajashekar Y (2014) Non-target effects of botanicals on beneficial arthropods with special reference to Azadirachta indica. In: Singh D (ed) mode of action of plant-derived natural insecticides. Springer, New Delhi, pp 323-345

Stark JD, Walter JF (1995) Neem oil and neem oil components affect the efficacy of commercial neem insecticides. J Agric Food Chem 43: $507-512$

Vargas RI (1989) Mass production of tephritid fruit flies. In Robinson AS, Hooper G (eds): world crop pests vol 3B, fruit flies Elsevier science publishers BV Amsterdam (Nederlands), pp 141-151

Vontas J, Hernández-Crespo P, Margaritopoulos JT, Ortego F, Hai-Tung Feng H, Mathiopoulos KD, Hsu J (2011) Insecticide resistance in Tephritid flies. Pestic Biochem Physiol 100:199-205

Zari T, Al-Attar AM (2011) Therapeutic effects of olive leaves extract on rats treated with a sublethal concentration of carbendazim. Eur Rev Med Pharmacol Sci 15:413-426

Publisher's note Springer Nature remains neutral with regard to jurisdictional claims in published maps and institutional affiliations. 